\title{
Grundkurs Thoraxröntgen
}

Hamer O, Zorger N, Feuerbach S, Müller-Wille R

Heidelberg: Springer Verlag 2012, 250 S., 350 Abb. mit CD-ROM, 49,95€

ISBN 978-3-642-17790-3

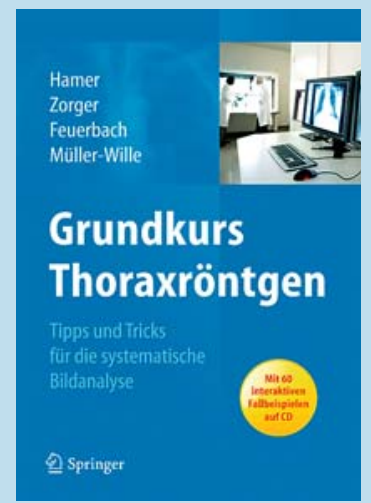

Den Autoren ist in ihrem Vorwort zuzustimmen: die Interpretation der Schnittbildverfahren fällt den meisten Kolleginnen und Kollegen mittlerweile nicht selten leichter als die des Röntgen-Thorax. Das gilt offenbar sogar für Radiologen: die Röntgenthoraxaufnahme soll jeder sozusagen naturgegeben interpretieren können, aber viel mehr Aufmerksamkeit beansprucht die neuere Hightech-Bildgebung; in der Folge geht zunehmend die Fähigkeit verloren, diese wohl anspruchsvollste radiologische Untersuchung zu beherrschen. Ich erinnere mich wehmütig an Professor Thurn an der Universität Bonn, einen Meister der Radiologie, der keinen Mitarbeiter zum Facharzt machte, der den Röntgen-Thorax nicht im Schlaf beherrschte. Denn diese Untersuchung ist weiterhin ganz zentral in der internistischen und vor allem auch pneumologischen Diagnostik. Keiner sollte sich Facharzt nennen, der diese Diagnostik nicht zu nutzen und zu schätzen weiß. Man muss ja nicht gleich wie Hans Castorp eine Röntgenthoraxaufnahme seiner Madame Chauchat in der Brusttasche tragen.

Der „Grundkurs Thoraxröntgen“ ist daher ein ganz wichtiger Beitrag zur Erhaltung dieser so zentralen Untersuchungstechnik. Der Aufbau ist bestechend klar: Technik, Bildqualität, Systematik der Bildanalyse, Normalbefund (entlang der Systematik), Pathologien (erneut entlang der Systematik) sowie Fallbeispiele. Man könnte ins Schwärmen kommen angesichts der perfekten Didaktik in der Darstellung, der fast 600 eindrücklichen Beispielbilder, begleitet durch eine Vielzahl gelungener Schemabilder, die sich sofort einprägen. Das Phänomen der „Satisfaction of search" etwa, des Übersehens von Befunden angesichts eines ins Auge stechenden Hauptbefundes, wird man nie mehr vergessen: Das Beispiel zeigt ein Bild eines Patienten, der einen Löffel verschluckt hat - darüber hinaus auch eine Zahnbürste, wenn man denn noch genau hinzuschauen vermag angesichts dieses unglaublichen Löffels da im Ösophagus.
So liest man dieses Werk mit großem Gewinn, unabhängig vom Stand des Vorwissens; Klarheit und Systematik macht einfach auch Freude. Die beigefügte CD liefert noch 60 interaktive Fallbeispiele. Wer dann noch lediglich Befunde der Radiologen liest, ohne sich die Bilder selbst anzuschauen, dem ist nicht zu helfen.

Kleinere Unvollkommenheiten sind zu benennen: Einige Bilder sind zu klein und liefern nur undeutlich die Befunde, auf die es ankommt - wo kann das etwa mehr gelten als bei der Lungenstauung und diesen Kerley-Linien. Hier wären größere Bilder bzw. Ausschnittsvergrößerungen angemessen gewesen. Das Pneumonie-Kapitel würde von einem Gespräch mit einem Pneumonie-Experten profitieren; obwohl die „atypische Pneumonie“ weitgehend verabschiedet ist, konnte man sich von der Erregerzuordnung zu Infiltraten noch nicht trennen, wohingegen die unterschiedlichen erregerabhängigen Rückbildungszeiten keine Erwähnung finden. Die Emphysemdiagnostik hätte noch ein wenig vorsichtiger gehalten bleiben können, angesichts der Tatsache, dass nahezu alle Radiologen schnell bei der Hand sind, ein Emphysem zu diagnostizieren. Bedenklicher ist die Entscheidung der Autoren, „Entitäten, bei denen die konventionelle Thoraxaufnahme keine Rolle spielt (z.B. fibrosierende Lungenerkrankungen und die Lungenembolie) oder seltene Diagnosen“ bewusst nicht zu besprechen. Denn man möchte widersprechen; die Thoraxaufnahme spielt durchaus noch eine Rolle bei den genannten Entitäten und die hätte man beschreiben müssen. Schließlich wird das Werk nicht dem auf dem Buchrücken verkündeten Anspruch gerecht, auch dienlich für die Intensivstation zu sein - dazu spielt die Bettaufnahme eine zu geringe Rolle. Hier könnte man allerdings auf das Komplementärwerk von G. Luska, Röntgenthorax auf Intensivstationen, ebenfalls im Springer Verlag, verweisen.

Dennoch ist das ein Werk, das in die Hand jedes Internisten und Pneumologen gehört, es sei denn, er lernt aus einer anderen Quelle. Doch viele davon gibt es nicht auf dem Markt. Und hier lohnt sich unbedingt ein Buch; denn veralten wird dieses erst, wenn das Thoraxröntgen einmal durch eine andere Technik abgelöst werden sollte; davon sind wir, soweit ich sehe, noch etwas entfernt. 